\title{
High School Mathematics' Teachers' Knowledge, Opinions, and Preferences about Types of Problems (An Example from Turkey)
}

\section{Seval Deniz KILIÇ}

Mugla Sitki Kocman University, Education Faculty, Elementary Mathematics Education, Muğla, Turkey. Email:denizk12@hotmail.com

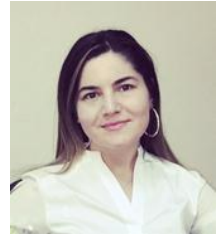

\begin{abstract}
Problem solving is the building block of mathematics. Different approaches have been exhibited throughout the history to solve the problems that are as old as the history of humanity. As a result of developments in mathematics education, the problems are divided into different types according to the solution methods. Determining the types of these problems and their solution methods is a very important gain for students studying mathematics education. Thus, the approaches of teachers to this subject, as a guide, will lead the way for their students. The purpose of this study is to determine mathematics teachers' knowledge, opinions, and preferences about the types of problems. The participants of the study were chosen among the mathematics teachers working in high schools located in a city in Turkey. The data sources of the study which adopted qualitative research methods are the interviews with the teachers, written exam questions, and lesson observations. For the data analysis, thematic content analysis and frequency and percentages were used. Considering the results obtained, the teachers do not recognize the non-routine problems and they do not use them in their exams and lessons. However, they find such problems meaningful and they want to use them in their courses if the necessary conditions are provided.
\end{abstract}

Keywords: Problems, Problems types, Non-routine problem, Mathematics teachers

Citation | Seval Deniz KILIÇ (2019). High School Mathematics' Teachers' Knowledge, Opinions, and Preferences about Types of Problems (An Example from Turkey). Asian Journal of Education and Training, 5(3): 429-439.

History:

Received: 7 June 2019

Received: 7 June 2019

Accepted: 13 August 2019

Published: 25 September 2019

Licensed: This work is licensed under a Creative Commons

Attribution 3.0 License $(\mathrm{cc})$ )

Publisher: Asian Online Journal Publishing Group
Funding: This study is produced from a Scientific Research Project Supported by the Republic of Turkey Mugla Sitkı Kocman University. No: 15/186. Competing Interests: The author declares that there are no conflicts of interests regarding the publication of this paper.

Transparency: The author confirms that the manuscript is an honest, accurate, and transparent account of the study was reported; that no vital features of the study have been omitted; and that any discrepancies from the features of the study have been omitte
study as planned have been explained.

study as planned have been explained.
Ethical: This study follows all ethical practices during writing.

\section{Contents}

1. Introduction 


\section{Contribution of this paper to the literature}

This study contributes to the existing literature by investigating the high school mathematics 'teachers' knowledge, opinions, and preferences about types of problems.

\section{Introduction}

Problem solving is the best expression of mathematical competence. According to Pólya (1945) the concept of problem is the foundation of mathematics, but for Hembree (1992) it is one of the controversial subjects in mathematics education. What can be considered as a problem changes from person to person (Zhu and Fan, 2006) day to day (Selden et al., 1999) and there are different definitions of problem in literature. A problem situation may not be a problem for another person (Marchis, 2013) or a situation which you consider a problem today may not be one for you tomorrow (Kilpatrick, 1985). Sometimes it is difficult to decide if the structure is a problem or an exercise because it changes from student to student (Zhu and Fan, 2006); a problem for a student may be an exercise for the other one (Marchis, 2013). The important thing is that the problem has a solution different from the common ways and methods because the "problems" that are solved via common ways and methods are not real problems (Fong, 1996). In addition to this, it is known that "real problems" have not always been used in mathematics classes. For example, teachers sometimes use problems which are usually believed to be known by the person who solves them, contain numerical questions, and arrive at an answer as a result of mathematical operations by using the data in the text (Lester, 1987; Selden et al., 1989; Özmen et al., 2012). The reason for this is that such problems hold many facilities both for the teachers and students (Verschaffel, 2002). Such problems which are also called as word problems and supposed to look familiar to the person who solves them contain numerical data and arrive at an answer as a result of mathematical operations by using the data in the text (Greer et al., 2002). Word problems may provide experiences for real-world situations, motivate students to understand the realworld problems, and help students develop creative and critical thinking and problem-solving skills (Chapman, 2006). However, because this situation enables to get to a result directly by using the data, it is far from the realproblem structure as stated by Lester (1987). Although the word problems whose traces were encountered similarly in different cultures in history, their purposes are not exactly known and they have reached today without being questioned much (Greer et al., 2002).

In addition to "real" and "word" problems, some sources divide the problems into two types: problems that could be solved easily (Verschaffel, 2002) or problems that need more thought process. The first one is called "routine" problems and the second one is called "non-routine" problems (Mahlios, 1988; Arslan and Altun, 2007; Marchis, 2013). But the classifications for the problems are not only limited to these. Charles and Lester (1982) classified the problems as standard and non-standard types and real-life and puzzle types. Lianghuo and Yan (2000)also classified problems in their comprehensive research:

- Routine and non-routine problems.

- Traditional and non-traditional problems.

- Non-traditional problems.

i) Problem posing problem.

ii) Puzzle problem.

iii) Project problem.

iv) Journal task.

- Open-ended and closed-ended.

- Application and non-application.

- Application problems.

i) Fictitiously application problems.

ii) Authentic application problems.

- $\quad$ Single step problems, multiple countable step problems, and multiple uncountable step problems.

- Problems with just sufficient information, problems with extra information, and problems with insufficient information.

- Problems in pure mathematical form, problems in verbal form, problems in visual form, and problems in a combined forms.

In addition to this, there are studies which include open-ended problems (problems that have multiple ways of solutions) in the non-routine problems (Krulik and Rudnick, 1993; London, 1993; Foong, 2002).

Since the 80 s, an understanding of education which focuses on learning process more than the subject taught (Chacko, 2004) and individual differences more than the strict education system (Saravanan, 2005) has started to be implemented. With the impacts of this education reforms, problems which students were engaged in open-ended, practical, and investigative tasks have been in demand by the end of the 1980s (Chan, 2007).

The open-ended problem tasks are usually thought of tasks which is likely to have more than a single correct solution and they offer students multiple approaches to the problem by putting little constraints on their methods of solution (Hancock, 1995). According to Foong (2002) open-ended problems are "ill-structured" because they comprise missing data or assumptions with no fixed procedures that guarantee a correct solution. Van (1996) in his study which used open ended problems stated that when students were given incomplete data, making their own assumptions would be beneficial. In addition to this, Hembree (1992) found that unnecessary information made the problem more difficult at each grade level. Because open-ended problems foster high-order thinking skills, it is considered that when students learn via problems, memorization will be hindered (Hiebert et al., 1996).

Non-routine problems are used to benefit from the open-ended problems which allow multiple solutions and get rid of the disadvantages of the "ill-structured" open-ended problems (Hembree, 1992) because non-routine problems are situations which are challenging for an individual to solve and there is not a direct method or an algorithm to use for the solution (Blum and Niss, 1991). Many factors as well as mathematical reasoning are mentioned for the development of problem-solving skill. Comprehension and proof skills are required for 
mathematical reasoning (Hembree, 1992; Niss, 2011). This is only possible with an understanding of education which aims at development of problem-solving skills. As cited in Liljedahl (2008) from Dan Kleitman, non-routine problems are problems for which there is no predictable approach or pathway for solution. You must be unsuccessful with your attempts and you must solve either with a sudden inspiration or instinct.

As it is seen, there are different definitions for non-routine problems. However, the common point is that nonroutine problems are suitable for developing mathematical skills, revealing individual differences, and drawing student attention. Non-routine problems in this study will mean mathematical problems which do not have only one solution and strategy and require higher-order thinking skills. Such problems can be associated with a specific mathematics topic or with daily life.

There are a lot of studies in literature which state that the use of non-routine problems foster students' problem-solving skills (Hembree, 1992; Guven et al., 2016). Thus, it is important to use non-routine problems in mathematics courses. Therefore, it is primarily important to identify what types of problems teachers benefit from.

\subsection{Types of Problems Mathematics Teachers Use in their Classes}

There are different studies about what types of problems mathematics teachers benefit from in their classes. According to this research, teachers mostly examine their students' operational skills in routine problems and whether or not they make calculations (Lester, 1987). Foong and Koay (1997) stated that different mathematical operations and calculations were performed in schools and problems similar to the previous ones were encouraged to be used; however, this situation caused students to be detached from the real life and to use cliché opinions. Guven et al. (2016) found that teachers mostly used the routine problems included in the curriculum. Moreover, they benefited from the stereotyped questions in their exams (Bekdemir and Baş, 2017). In addition to this, it was stated that when teachers are guided properly, they would include non-routine problems in their courses (Ho and Hedberg, 2005).

\subsection{The Aim of the Research}

The aim of this research is to investigate high school mathematics teachers' knowledge, opinions, and preferences related to the types of problems. There are different studies in literature which focus on the problems or questions and the strategies (Arslan and Altun, 2007; Swanson et al., 2014) teachers used in their courses (Özmen et al., 2012; Guven et al., 2016) and exams (Bekdemir and Baş, 2017) however, there are not any studies with broad sampling in literature which investigate teachers' knowledge, opinions, and preferences related to the different types of problems . Based on the need that schools are the preview of real life, it is important that studies must be carried out with students studying in primary and secondary schools to develop their problem-solving skills so that they will become ready for the real life. Thus, the knowledge, opinions, preferences, and attitudes of teachers who also play the role of a guide in such studies related to problem-solving are meaningful as they will affect the educational process of the students who they are going to train (Verschaffel et al., 1997; Chen et al., 2011) because it is known that the teachers who have knowledge and positive attitudes intended for the nature of nonroutine problems prefer such problems in their classes (Ho and Hedberg, 2005). Due to all these reasons, this research aimed at determining high school mathematics teachers' knowledge, opinions, and preferences related to the non-routine problems. The research sought to answer the following questions:

1. Do teachers know non-routine problems?

2. Do they find such problems meaningful and beneficial?

3. Do they include such problems in their lessons and exams?

\section{Method}

Case study, one of the qualitative research methods, was used in this study. Considering the principles of the case study (Hitchcock and Hughes, 1995) as it is concerned with a rich and vivid description of events relevant to the case, variety of data sources were used to investigate the high school mathematics teachers' knowledge, opinions, and preferences related to the non-routine problems. Data sources contain open-ended interview forms, exam questions, and lesson observation Figure 1. The purpose here is to seek answers for the research problems correctly by using the different data sources (Turner et al., 2015).

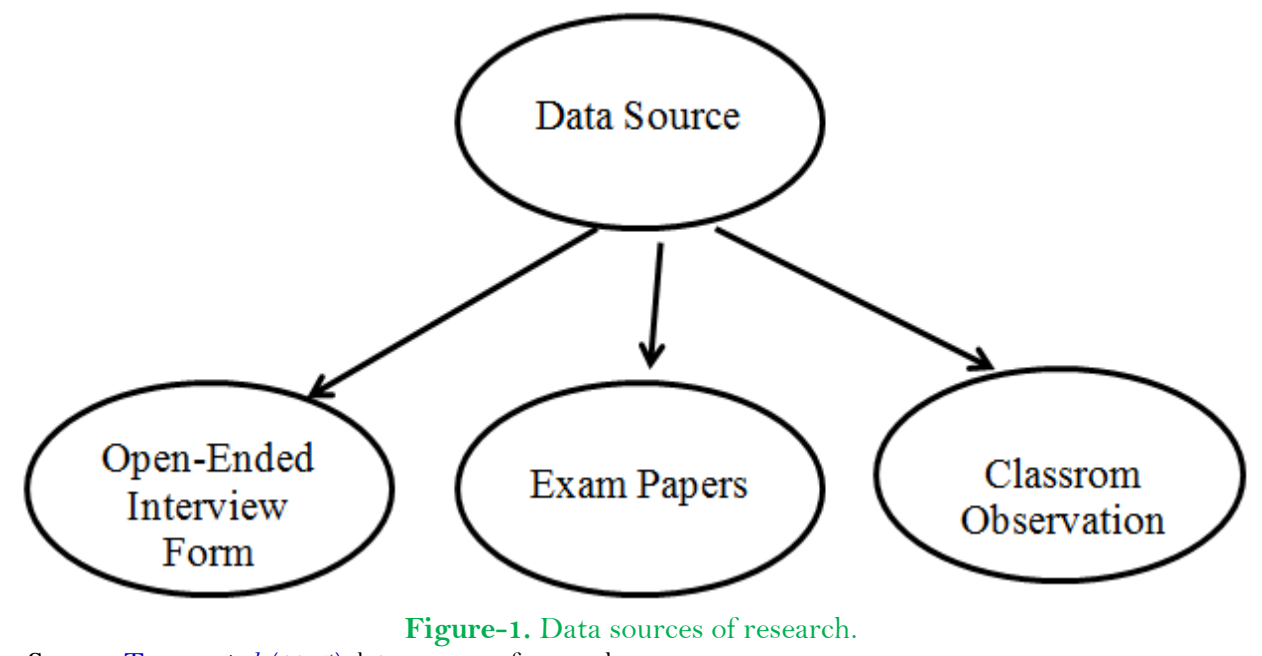

Source: Turner et al. (2015) data sources of research. 


\subsection{Participants}

The participants of the study are the mathematics teachers working in state high schools located in a city in Turkey in 2015-2016 education year. The school lists were obtained from the Provincial Directorate of National Education to determine the particular schools. All schools located in the city centre were involved in the study. Two mathematics teachers were chosen from each high school as a sampling. While choosing the teachers, convenience sampling was used and they were chosen on voluntary basis. However, because there is only one teacher in some schools, one teacher could participate in the study to represent that school. Considering this, 25 teachers from a total of 15 schools, 1 science school (SS), 5 anatolian high schools (AS), 6 vocational high schools (VS), 1 religious vocational high school (RS), 1 fine arts high school (FAS), 1 social sciences high school (SSS) were involved in the study. Table 1 presents the distribution of the participant teachers in the study according to the types of schools they work, gender, faculties they graduated from and the length of service (High schools except for science and anatolian high schools were evaluated within the context of vocational high schools).

\begin{tabular}{c|c|c|c}
\hline \multicolumn{4}{c}{ Table-1. Participant and school type information. } \\
\hline \multirow{3}{*}{ School type } & & Frequency (N=25) & Percentage (\%) \\
\cline { 2 - 4 } & SS & 2 & 8 \\
\cline { 2 - 4 } & AS & 8 & 32 \\
\cline { 2 - 4 } Sex & VS & 15 & 60 \\
\cline { 2 - 4 } & Female & 12 & 48 \\
\hline Graduated & Male & 13 & 52 \\
\hline Faculty & Science & 13 & 52 \\
\hline Seniority & $0-4$ & 12 & 48 \\
\cline { 2 - 4 } & $5-10$ & 1 & 20 \\
\cline { 2 - 4 } & $11-14$ & 5 & 28 \\
\cline { 2 - 4 } & $15-20$ & 7 & 48 \\
\hline
\end{tabular}

\subsection{Data Collection}

A semi-structured interview form, written exam papers, and the notes taken during the lesson observation were used as data collection tools.

Semi-structured Interview Form: The questions included in the semi-structured interview form were asked as open-ended in order to reveal teachers' thought processes (Lofland, 1971). 12 different problems were presented in the interview form and the teachers were asked to examine these problems. These problems are routine (word), noun-routine, and open-ended types of problems. Some of these problems were taken from the literature and some of them were selected from different course books and theses with an educator from the field. An example representing routine, non-routine, and open-ended problems used in the study were presented in Table 2.

\begin{tabular}{|c|c|c|c|c|c|c|c|c|c|c|c|}
\hline Type & \multicolumn{11}{|l|}{ Problem } \\
\hline $\begin{array}{l}\text { Routine problem } \\
\text { (word problem) }\end{array}$ & \multicolumn{11}{|c|}{$\begin{array}{l}\text { An item is sold for } 13.65 \mathrm{TL} \text { at a discount rate of } 35 \% \text {. What is the real price of this item } \\
\text { before the discount? (Altun, 2004). }\end{array}$} \\
\hline $\begin{array}{l}\text { Non- routine } \\
\text { problem }\end{array}$ & \multicolumn{11}{|c|}{$\begin{array}{l}\text { The base of an isosceles triangle is the diameter of the circum circle. Compare the area of } \\
\text { this triangle inscribed in a circle with the area of the circle (Kılıc, 2011). }\end{array}$} \\
\hline \multirow[t]{4}{*}{ Open-ended problem } & \multicolumn{11}{|c|}{$\begin{array}{l}\text { A construction company wants to hire workers for a project. This project must be } \\
\text { completed in five days and it allows hiring maximum } 14 \text { workers in a day. Suppose that } \\
\text { you are the director of this company and hire workers from different companies. What do } \\
\text { you do to keep the cost low? Suppose that each worker produces the same amount of daily } \\
\text { work activity. Below is given the number of workers in the companies from which the } \\
\text { workers will be hired. When a company is chosen, all of the workers will work on that } \\
\text { day. Not every company has to be chosen but a company can be chosen only once (Chan, } \\
\text { 2007). }\end{array}$} \\
\hline & Company & $\mathrm{A}$ & B & $\mathrm{C}$ & $\mathrm{D}$ & $\mathrm{E}$ & $\mathrm{F}$ & G & $\mathrm{H}$ & I & $\mathrm{J}$ \\
\hline & $\begin{array}{l}\text { No. of } \\
\text { workers }\end{array}$ & 8 & 12 & 2 & 3 & 7 & 6 & 9 & 10 & 11 & 5 \\
\hline & Cost (\$) & 600 & 1400 & 300 & 400 & 500 & 600 & 700 & 800 & 1200 & 500 \\
\hline
\end{tabular}

Source: The problems retrieved from works of Altun (2004), Kılıç (2011), Chan (2007).

Then, the teachers were asked four semi-structured questions. The following are the questions:

1. If you can group these problems on your own, how and in what ways can you group them? If you are to name them, what will you call each group? Why? Please explain.

2. If you think the problems with their solutions, which problem group is the most meaningful, beneficial, and practical among the groups in your opinion? Why?

3. Which group of problems do you prefer to use? Are there any types of problems you have encountered for the first time? Do you think of using problems belonging to different groups? If your answer is negative, can you please explain your reasons?

4. What types of problems do you prefer to use in your courses and exams? Are the problems you use similar to these ones? Please explain.

The written answers were collected and there was not a limitation on the response time.

Written exam papers: The second data collection tool is the teachers' exam questions. Exam papers belonging to different types of schools were obtained in order to represent each one of the different schools. These papers were analysed via documents analysis. Document analysis is the review of written documents and visual materials 
containing information about the target phenomena or phenomenon (Yıldırım and Şimşek, 2006). While examining the questions, whether or not they involved characteristics of three different types of problems was paid attention.

Lesson observation: The third data source is the observation of an example lesson. Although an observation of a single course does not allow to make generalization for that teacher (Kane and Staiger, 2012) it will give some ideas about how much it is appropriate to the standards of the desired lesson (Charalambous and Praetorius, 2018). Here, as lesson standards, the focus was on to what extent the examples belonging to these three different types of problems were involved.

\section{Data Analysis}

The data obtained from the interview form were performed in three stages. The researcher read the data obtained from the interview form a few times. Then, thematic content analysis was used for the analysis of the data obtained from the interview form. This analysis is used to describe the experiences or characteristics of a group by obtaining themes and different codes within data (Neuendorf, 2002). The codes belonging to a set of data related to the topic was generated and discrete themes were obtained to determine the relationship between the codes obtained in this research. In this process, the stages defined by Braun and Clarke (2006) were followed. According to this, first of all, the data obtained were analyzed and then they were examined in depth. The purpose here is to internalize the data and control the data group. Then, in line with the research questions, draft coding was made and possible models were tried to be found. For this, associated words and expressions were highlighted with the same colour pen and separated from the others. In this stage, an attempt was made to behave objectively. In the second stage, analyses were re-read and re-coded to prevent any kind of error. After that, the appropriate codes were combined and sub-themes and themes were developed. After this operation, whether or not the themes represented all the data obtained were discussed with the second researcher. The data were revised for the themes with which there was not a settlement with and necessary corrections were made. In the last stage, the themes and codes were represented in tables and they were supported with the direct quotes obtained from the participants. Every stage in the data collection tools and analysis process were explained in detail to provide validity (Braun and Clarke, 2006). In addition to this, frequencies and percentages belonging to the findings were given.

For the analysis of exam papers and lesson observation, the characteristics of routine and non-routine problems were particularly used as a framework (Charalambous and Praetorius, 2018). The questions prepared according to this were included in the "exam question analysis" and "lesson observation" forms were given below:

1. Does the problem have multiple solution methods?

2. Does the problem form a basis for making a detailed reasoning and discussion of different solutions?

3. Does the problem have a structure that allows the individual who solves the problems to change the illstructured problem?

\section{Findings}

\subsection{Findings Related to the Teachers' Knowledge of Non-Routine Problems}

To begin with, whether or not the teachers were familiar with the non-routine problems were questioned. Thus, they were asked to group the problems and give names to each group. The codes and themes obtained as a result of the content analysis were presented in Table 3.

Considering Table 3, it is found that teachers classified the problems according to the "topic", "method", and "structure". When Table 3 is examined, it is observed that the problems were mostly discussed structurally (\%47). In this group, it is understood that the teachers named the problems on their own. The point that draws attention here is that the teachers tried to categorize the problem without considering the solution of the problem. Routine and non-routine problems were discussed in the group of solution methods. Only two teachers noticed the difference $(8 \%)$. One of these teachers stated that she attended an in-service training about problem-solving skills before (religious vocational high school, female). In addition to this, relatively little reference was made for the classification according to the "solution method" (\%27,5).

On the other hand, when the teachers were asked whether or not they encountered such problems, only three teachers stated that they were the types of problems they had never met before. Their direct quotations were cited as follows. "It is the first time I have ever encountered a question type as the $7^{\text {th }}$ question" (male, vocational high school). "Question 12 is different. I don't think of using it. I don't believe that it works a lot" (female, anatolian high school). "I used similar questions like these ones, but I can say that I have seen questions 8 and 12 for the first time (male, social sciences high school)”.

Among the problems mentioned, problems 7 and 8 are non-routine problems but the $8^{\text {th }}$ problem is related to the real-life. The other teachers stated that they were familiar with all of the problem types.

The distribution of the themes related to the types of problems obtained from the teachers' views according to the schools was presented in Table 4 .

When Table 4 is examined, it is found that among the types of schools, the vocational high schools focused mostly on the methods of solution whereas science and social sciences schools paid the least attention on methods of solution. 
Table-3. Distribution of codes and themes from content analysis.

\begin{tabular}{|c|c|c|c|}
\hline Themes & Code & Frequency & $\%$ \\
\hline Problem's theme & $\begin{array}{l}\text { Percent, geometric, ratio-proportion, geometric sequence, } \\
\text { arithmetic mean, pattern, geometric shape, geometry } \\
\text { experience question, number problems, percentage } \\
\text { calculation, sets, induction, number sequences, ratio and } \\
\text { proportion, obeb-okek, interpretation of probability, } \\
\text { name, according to the subject type, ygs and lys } \\
\text { questions, basic math problems, number problems, profit- } \\
\text { loss problems, function problems, series problems, set. }\end{array}$ & 25 & 25,5 \\
\hline Solution method & $\begin{array}{l}\text { Trial and error, induction, deduction problems, trial-and- } \\
\text { error problems, trial-and-error group, routinely solved, } \\
\text { solved outside of the routine, according to the } \\
\text { information required to solve the problem, according to } \\
\text { the solution methods, according to the feature desired to } \\
\text { be developed in the solution, using modeling and variable } \\
\text { question types type of question, type of question, type of } \\
\text { question which can be solved by visual aid, question style } \\
\text { that can be solved by stepping step by step, questioning } \\
\text { reasoning, drawing a figure, interpreting, using } \\
\text { information, interpreting information, revealing truth, } \\
\text { questionable question, comprehending and applying } \\
\text { knowledge, according to strategy choice, judgment, } \\
\text { ability, logic, knowledge. }\end{array}$ & 27 & 27.5 \\
\hline Structure of problem & $\begin{array}{l}\text { Daily life problems, mathematics in daily life, tasteful } \\
\text { math problems, process problems, scientific problems, } \\
\text { analysis problems, inductive problems, research- } \\
\text { examination problems, logic and reasoning, abstract } \\
\text { thinking, basic concepts, logic and reasoning, logic } \\
\text { questions, process questions, open problems, modeling } \\
\text { problems, logic execution, everyday life, three } \\
\text { dimensional thinking, geometric thinking, attention } \\
\text { question, abstract process question, question of algebra, } \\
\text { question of mathematics of self-confidence, question of } \\
\text { knowledge level, question of industrial accounting, digital } \\
\text { logic question, contradiction question, think, imagine, } \\
\text { comment, find in mind question, routine problem, non- } \\
\text { routine problem, open-ended question of analysis- } \\
\text { synthesis, grouping by question types, if there is a scan or } \\
\text { exam situation, according to the degree of difficulty, } \\
\text { suggesting question, canonical question, known routine } \\
\text { math problems, ask our knowledge guiding questions, } \\
\text { suggestive, canonical, comparative problems, closed type, } \\
\text { open-ended problems, mathematical theoretical problems, } \\
\text { mathematical, logical, problems associated with daily life, } \\
\text { problems of straight logic. }\end{array}$ & 46 & 47 \\
\hline
\end{tabular}

Source: Codes and themes retrieved from interviews with teachers.

Table-4. Distribution of themes by school types.

\begin{tabular}{c|c|c|c|c|c|c|c|c}
\hline \multicolumn{10}{c}{ Frequency } \\
\hline Problem types (\%) & SS & AS & VS & RS & SSS & FAS & Sum frequency & Percentage \\
\hline Problem's theme & 1 & 3 & 9 & 1 & 11 & - & 25 & 25,5 \\
\hline Solution method & - & 4 & 19 & 3 & - & 1 & 27 & 27,5 \\
\hline Structure of problem & 8 & 13 & 16 & 5 & 4 & - & 46 & 47 \\
\hline
\end{tabular}

Source: Themes retrieved from interviews with teachers.

\subsection{Findings Related to the Teachers' Opinions about Non-Routine Problems}

In this section, the teachers were asked to determine the most meaningful, useful, and practical problem groups out of the groups they formed when they thought with their solutions. As stated in the previous section, the teachers are not expected to know the names of the types of problems. Considering the teachers' preferences of problems, the types of these problems were determined. For example, it is understood that the teachers who thought that the problems 1 and 8 were meaningful found non-routine problems meaningful or the teachers stated their views directly. For example, "I find the problems meaningful in everyday life". In this case, the teacher's statement was accepted without matching the problems. In addition to this, there were teachers who referred to the problems in different categories at the same time. But, the dominant ones from their category preferences were prioritized. According to the findings, the distribution of the most meaningful problem structures by the teachers were presented in Table 5 .

When Table 5 is examined, it is found that the teachers found the non-routine problems meaningful at a dominant rate (\%36). In addition to this, the teachers considered real life (\%20) and reasoning (\%16) problems as meaningful.

When an investigation was made considering the types of schools, it was observed that science high school teachers preferred real life (\%50) and logical reasoning(\%50) problems, Anatolian high school teachers preferred predominantly non-routine $(\% 37,5)$ and real life problems $(\% 37,5)$, vocational high school teachers found mostly non-routine problems useful (\%40). Similarly, all religious vocational high school teachers stated that non-routine problems were beneficial (\%100). Moreover, all the teachers who preferred purposive problems are vocational high 
school teachers. On the other hand, the only teacher who found routine problems meaningful is a vocational high school teacher, too.

Table-5. Distribution of the most meaningful problem structures by the teachers.

\begin{tabular}{l|c|c|c|c|c|c|c|c}
\hline Frequency & SS & AS & VS & RS & SSS & FAS & Sum frequency & Percentage (\%) \\
\hline Problem types & - & 3 & 4 & 2 & - & - & 9 & 36 \\
\hline Non routine & 1 & 3 & 1 & - & - & - & 5 & 20 \\
\hline Real life & 1 & 1 & - & - & 1 & 1 & 4 & 16 \\
\hline Reasoning & - & - & 3 & - & - & - & 3 & 12 \\
\hline Purposive & - & - & 1 & - & - & - & 1 & 4 \\
\hline Open-ended & - & - & - & - & 1 & - & 1 & 4 \\
\hline Number & - & 1 & - & - & - & - & 1 & 4 \\
\hline For university exams & - & - & 1 & - & - & - & 1 & 4 \\
\hline Routine & & - & & & 4 \\
\hline Sourc:
\end{tabular}

Source: Codes and themes retrieved from interviews with teachers.

\subsection{Findings Related to the Teachers' Preferences of Non-Routine Problems}

This section explored whether or not teachers included non-routine problems in their lessons. For this purpose, the responses obtained from the questions asked to the teachers and the questions teachers used in their lessons and exams were examined. The data obtained from the teachers' responses were presented in Table 6.

\begin{tabular}{|c|c|c|c|c|c|c|c|c|}
\hline \multicolumn{9}{|l|}{ Frequency } \\
\hline Problem types & SS & AS & VS & RS & SSS & FAS & Sum frequency & Percentage (\%) \\
\hline University exam & 1 & - & - & - & - & - & 1 & 4 \\
\hline Interpretation and process & 1 & - & - & - & - & - & 1 & 4 \\
\hline Mathematical thinking and acquisition & - & - & - & - & 1 & - & 1 & 4 \\
\hline Knowledge based & - & - & - & - & - & 1 & 1 & 4 \\
\hline Operational questions & - & 2 & 4 & - & - & - & 6 & 24 \\
\hline Real life and interpretation & - & - & 1 & - & - & - & 1 & 4 \\
\hline Logic, process, and curriculum-based & - & - & 1 & - & - & - & 1 & 4 \\
\hline Routine, curriculum-based & - & - & 1 & - & - & - & 1 & 4 \\
\hline Routine & - & 3 & 2 & 2 & - & - & 7 & 28 \\
\hline Non routine & - & 2 & 1 & - & - & - & 3 & 12 \\
\hline Curriculum-based & - & 1 & - & - & 1 & - & 2 & 8 \\
\hline
\end{tabular}

When Table 6 is examined, it is revealed that teachers mostly preferred operational questions (\%24) and routine problems (\%28). The percentages given for the problem types were obtained from the teachers' statements as it was in the previous section. Some teachers referred to problems in the interview form whereas some of them told the name of the problem type.

According to this, some of the problem types obtained show similarities with the other type. For example, with the operational questions (\%24), non-routine problem structure may have been implied. In this case, taking both parts together, the usage of problems containing routine operations could be considered $52 \%$. This means that $52 \%$ of the teachers prefer routine problems. On the other hand, the teachers who use non-routine problems are $12 \%$. In addition to this, the curriculum based problem types were explained in three categories: reasoning, operation, and curriculum based (\%4), routine and curriculum-based (\%4), and curriculum based ( $\%$ ). Thus, it can be stated that $16 \%$ of the teachers use the problems involved in the curriculum. An anatolian high school teacher who stated that he used very few non-routine problems said: "We use problems or ordinary types in the lessons and exams. The problems we use are similar to them. But not all of them. We use problems with direct result. Personally, I spare my course time once a week for special questions. In these lessons, I use contradictory problems. This is a section which involves questions that encourage thinking. However, I never use these problems in the exams."(anatolian high school, male). The explanation of the teacher who does not use non-routine problems can be given as an example: "I use routine problems in my lessons and exams. Unfortunately, the students who do not know its use with four operation skills and problems are not successful in the solution of non-routine problems. I use much more simplified versions of the first 6 problems" (religious vocational school, female). The teacher who used curriculum based and problems based on operations stated: "My practices consist of the simplest version of the knowledge. I ask questions at an operational level. The curriculum-course book and passing grade exam system implemented make it difficult for us to teach in project, research and interpretation format. Even, I encounter the answer "there is no internet" with the simplest research-data collection homework assigned as project work" (vocational high school, male). Three exam papers belonging to three types of schools were analyzed in order to support teachers' views.

\subsection{Written Exam Papers}

An example of an exam paper which exemplifies the questions used in vocational high school exams is given in Figure 2.

When Figure 2 is examined, it is seen that the questions are types of questions that require routine operations. On the other hand, when the written exam paper belonging to an anatolian high school is examined, it is found that the questions used were similar to the questions involved in the university exam preparation books. The examples of standard questions which do not need any discussion or interpretation are given in Figure 3. 


\begin{tabular}{|c|c|}
\hline \multicolumn{2}{|c|}{$\begin{array}{l}\text {... Vocational and technical anatolian high school 2015/2016 academic year 12th grade mathematics lesson } \\
\text { 2nd semester 2nd written exam questions. }\end{array}$} \\
\hline $\begin{array}{l}\text { 1- If the sum of half, } 1 / 4 \text { and } 1 / 5 \text { of a number is } 38 \text {, } \\
\text { what is this number? }\end{array}$ & 2- Which number is $40 \% 160 ?$ \\
\hline $\begin{array}{l}\text { 3- A father is } 35 \text { years old and his son is } 9 \text { years old. } \\
\text { How many years later would the father's age be three } \\
\text { times the age of his son? }\end{array}$ & $\begin{array}{l}\text { 4- How much is a product costing } 120 \text { TL for } 40 \% \\
\text { loss? }\end{array}$ \\
\hline
\end{tabular}

Source: The data were taken from a local school in Turkey under the ministry of national education.

\begin{tabular}{|l|l|}
\hline $\begin{array}{l}\text {... Anatolian high school 2015/2016 academic year 10th grade mathematics lesson 2nd semester 1st written } \\
\text { exam questions. }\end{array}$ \\
$\begin{array}{l}1-\text { What is the ordinate of the closest point of the parabola } \\
f(x)=-x^{2}+4 x+3 \text { to the line } y=2 x+5 ?\end{array}$ & $\begin{array}{l}3-y=-x^{2}+m x+m-2 \\
\text { Find the equation of the geometric location of the } \\
\text { peaks of the parabola. }\end{array}$ \\
\hline $2-$ & $\begin{array}{l}\text { 4- }\left(1+m^{2}\right) x^{2}-3 m^{2} x-1=0 \text { If the roots of } \\
\text { the equation are } x_{1} \text { and } x_{2}, \text { sort the numbers - } \\
1,1, x_{1} \text { and } x_{2} .\end{array}$
\end{tabular}

Source: The data were taken from a local school in Turkey under the ministry of national education.

However, when the questions used by the science high school teachers are examined Figure 4 it is revealed that the questions are similar to the questions frequently encountered in the university exam preparation books.

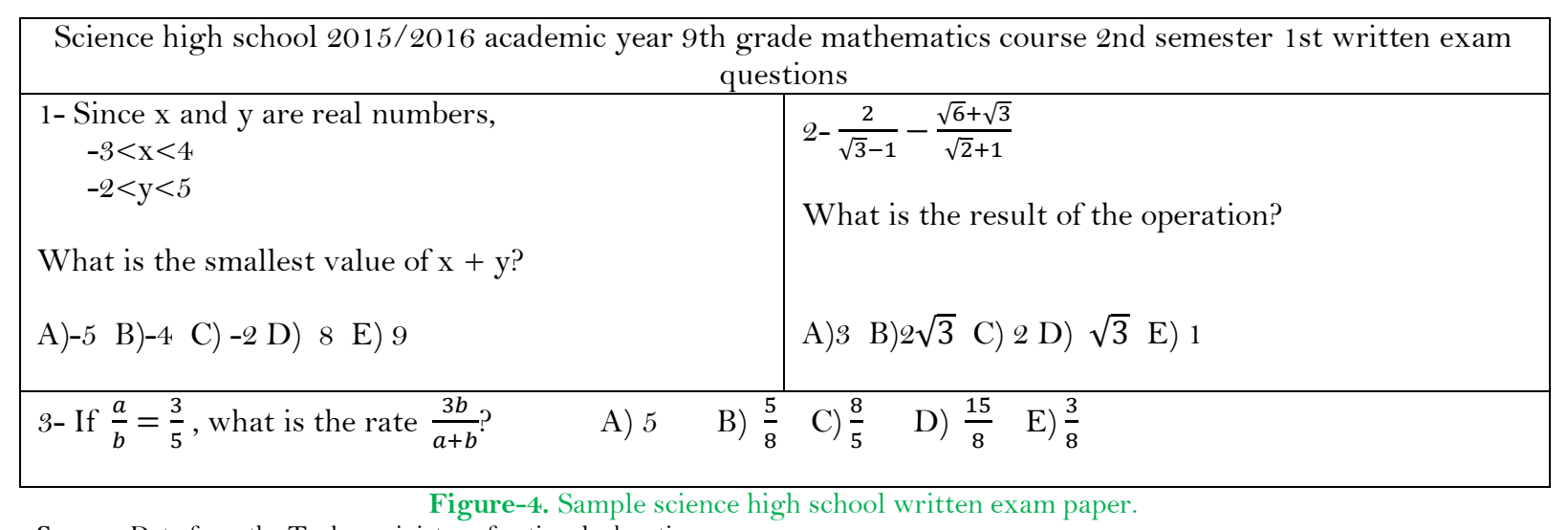

Source: Data from the Turkey ministry of national education.

Supporting Figure 4, the teacher's opinion who says that the questions are similar to the university exam questions can be given: "Because the examination system dominantly measures technical knowledge, our questions are usually parallel to the university entrance examination" (male, science high school).After examining the exam papers, the lesson in the $9^{\text {th }}$ grade level in a science high school was observed.

\subsection{Lesson Observation}

A teacher's 2 hour course in a science high school was observed by making an appointment before. The reason for the selection of the science high school is the expectation that the problems that need different thinking skills could be used by such schools which admit students with high points. When the teacher began the lesson, he solved a non -routine problem on the board. The problem solved in the classroom is like that: "Mostly 3 steaks could be put in a frying pan used for frying steak and a piece of steak could be cooked in 30 minutes. So, how many minutes at least are needed to cook 13 pieces of steak?"

When the problem is examined carefully, it is viewed that the solution could be reached by using different ways of solutions. When the teacher asked the question to the class, the first way of solution offered by the students was like that: "The pieces are put in the pan in threes and in 30 minutes, the first three pieces are cooked. Just like this, it is repeated three times, that is, totally 30 multiplied by 4 is equal to 120 minute, so 12 steaks are cooked. The remaining one steak is put in the pan and it is cooked for another 30 minutes. Therefore, the time spent will be 120 plus 30 is equal to 150 minutes".

The teacher was not satisfied with this answer and asked the class if they could find a different way of solution. After thinking sometime, students came up with a different answer: "Because it says at least, we must think in this way: let's put the steaks in threes and in three times, 9 steaks are cooked and that is 3 multiplied by 30 equals to 90 minutes. There are 4 steaks remaining. Take 3 of them and put them in the pan. That means there will be one piece of steak outside. We can cook one side of the 3 steaks in the pan in 15 minutes. Then, let's take out one of the steaks and put the remaining steak in place of it. Turn down the other two steaks to cook the other sides. The two steaks will be cooked completely 15 minutes later and the last steak's only one side is cooked. And totally it takes 120 minutes. There are two steaks, whose one sides are cooked and other 
sides are not cooked. We can cook the uncooked sides of these 2 steaks in 15 minutes. Thus, the total time is 120 plus 15 equals to 135 minutes". The teacher found this answer more useful and he appreciated the student who approached the problem differently.

Considering the structure of the problem solved in the lesson, the problem seems to be an example of nonroutine structure. The teacher was satisfied with the discussion environment in the classroom and supported students' contributions. The teacher continued the topic in his other course and used the routine questions he always used. At the end of the lesson, similar to the Anatolian highs school teacher whose opinion was taken, he stated that he used such problems rarely in his lessons and he definitely did not use them in his exams. Two teachers in science high schools which admit students with higher points were asked why they did not frequently use such problems. The first teacher stated the following: "We do not use problems in every lesson because it is difficult to find problems about each topic. Moreover, it takes a lot of time. It is more reasonable to study problems in the $9^{\text {th }}$ grade in "problems" subject." The other science high school teacher answered the question in that way: "We can't ask difficult or open-ended questions in the exams because our students and parents' are highly anxious about the grades. It is difficult to grade the multiple ways of solutions. Thus, we ask questions which are based on simple operations and do not need a lot of reasoning".

\section{Results and Recommendations}

When the teachers were asked to classify the routine, non-routine, and open-ended questions in interview form, the themes revealed indicate the ways of solution at a low level. Considering this, teachers classified the $27,5 \%$ of the problems according to the methods of solutions. The teachers categorized the $72,5 \%$ of the problems on the basis of structured (enjoyable mathematical problems, operational problems and etc.,) and topic (profit and loss problems, function problems and etc.). This case may not reflect the core of the "real" problems because nonroutine problems are the problems which cannot be solved by using the known algorithms, formula, or methods (Blum and Niss, 1991; Fong, 1996) but provide opportunities for different ways of solutions (Fong, 1996; Chan, 2007). Thus, it can be expected that the statements which reflect the problem best are the expressions which refer to the problem's such characteristics. However, it is understood from nearly $73 \%$ of the teacher explanations that they do not focus on the problem's method of solution and results. However, the most important characteristic of non-routine problems is that they have a structure which allows multiple solutions and reveal individual differences (Fong, 1996; Chan, 2007). Out of 25 teachers participating in the study, 22 of them stated that they saw all the types of problems before, but only two teachers used the expression of "non-routine problem". This case reveals that $92 \%$ of the teachers do not have adequate knowledge about the non-routine problems and cannot identify such problems. The teachers' opinions and attitudes about problem solving are significant in terms of impacts on the educational process of the students whom they are going to teach (Verschaffel et al., 1997; Chen et al., 2011). Due to these reasons, teachers must be enlightened about non-routine problems and their purposes. Thus, in-service training can be organized.

Teachers were asked what type of problems they found meaningful and useful to answer the second research question. Non-routine problems are identified as the most meaningful problems (\%36). This case reveals that teachers shared the opinion that these problems would be beneficial. This result is compatible with the previous studies (Asman and Markovits, 2009).

The third result obtained in the study exhibits what types of problems teachers benefit from in their lessons and exams. Similar to the previous studies (Foong and Koay, 1997; Özmen et al., 2012) 52\% of the teachers prefer routine problems. Only 12 of the teachers prefer non-routine problems. This case reveals that the teachers have a tendency to use "non-routine" problems rarely in their lessons. This finding obtained refers to a very interesting case. Although teachers think that non-routine problems are meaningful and useful, they do not prefer to use them. Considering the drawbacks of using only routine problems in the lessons (Özdogan and Kula, 2007) it seems meaningful to explore the teachers' reasons for not using non-routine problems. There are a few reasons for these according to the findings obtained. One of the reasons is that teachers think that the level of readiness of the students is not adequate. Most students pass into the next grade level without acquiring the knowledge and concepts which they had to gain in the previous grade levels. The teachers state that these students lack basic knowledge and they will not be able to solve non-routine problems. Because they have not met non-routine problem structures before, it becomes challenging even for the most successful students during the solution process. However, the studies carried out reveal that such problems will develop students' problem-solving skills (Ishida, 2002; Chan, 2007). The other reason stated by the teachers is that solving such problems is time consuming and they have a curriculum which they have to catch up with. In addition to this, the problems properly involved in the curriculum can be used. According to the research results, some of the teachers think that problems must be studied only in the "problems" topic and mention the difficulties of finding such problems. However, today it is possible to reach international books which include non-routine problems belonging to the different subjects of mathematics (Lianghuo, 2011). The importance of problem solving was emphasized in the New Turkish Secondary Education Curriculum (M.E.B) (2018). Thus, it is required that an understanding of education which prioritizes the importance of problem solving should be developed within the teachers. In addition to the courses, it is revealed that the teachers do not use non-routine problems in their exams. Asman and Markovits (2009) reached the similar results. The reasons why teachers do not use non-routine problems in their exams is that students and parents are anxious about the grades because they determine that there are very few students who can solve the non-routine problems. Moreover, it is stated that because such problems are not asked in university examination, these problems do not draw interest. Including non-routine problems in the student selection and placement examination can draw the attention on these questions. Thus, considering that solving non-routine problems is a "useful" method, students and parents can attach the necessary importance to this activity.

\section{References}

Altun, 2004. Mathematics teaching in high schools. Third book. 5th Edn., Bursa: Current Publishing

Arslan, C. and M. Altun, 2007. Learning to solve non-routine problems. Elementary Education Online, 6(1): 50-61. 
Asman, D. and Z. Markovits, 2009. Elementary school teachers' knowledge and beliefs regarding non-routine problems. Asia Pacific Journal of Education, 29(2): 229-249.Available at: https://doi.org/10.1080/02188790902859012.

Bekdemir, M. and F. Baş, 2017. Analysis of the questions used by mathematics teachers in exams in terms of conceptual and operational knowledge. Nineteen May University Journal of Faculty of Education, 36(1): 95-113.

Blum, W. and M. Niss, 1991. Applied mathematical problem solving, modelling, applications, and links to other subjects—state, trends and issues in mathematics instruction. Educational Studies in Mathematics, 22(1): 37-68.Available at: https://doi.org/10.1007/bfoo302716.

Braun, V. and V. Clarke, 2006. Using thematic analysis in psychology. Qualitative Research in Psychology, 3(2): 77-101.Available at: https://doi.org/10.1191/1478088706qp063oa.

Chacko, I., 2004. Solution of real-world and standard problems by primary and secondary school students: A Zimbabwean example. African Journal of Research in Mathematics, Science and Technology Education, 8(2): 91-103.Available at: https://doi.org/10.1080/10288457.2004.10740564.

Chan, C.M.E., 2007. Using open-ended mathematics problems: A classroom experience (Primary). In C. Shagar \& R. B. A. Rahim (Eds.), Redesigning pedagogy: Voices of practitioners. Singapore: Pearson Education South Asia. pp: 129-146.

Chapman, O., 2006. Classroom practices for context of mathematics word problems. Educational Studies in Mathematics, 62(2): 211230.Available at: https://doi.org/10.1007/s10649-006-7834-1.

Charalambous, C.Y. and A.-K. Praetorius, 2018. Studying mathematics instruction through different lenses: Setting the ground for understanding instructional quality more comprehensively. Zentralblatt for Didactics of Mathematics, 50(3): 355-366.Available at: https://doi.org/10.1007/s1 1858-018-0914-8.

Charles, R.I. and F.K. Lester, 1982. Teaching problem solving: What, why and how. Palo Alto, CA: Dale Seymour Publications.

Chen, L., W. Van Dooren, Q. Chen and L. Verschaffel, 2011. An investigation on Chinese teachers' realistic problem posing and problem solving ability and beliefs. International Journal of Science and Mathematics Education, 9(4): 919-948.Available at: https://doi.org/10.1007/s10763-010-9259-7.

Fong, H.K., 1996. An integrated approach for teaching mathematical problem solving. The Mathematics Educator, 1(1): 36-44.

Foong, P.Y., 2002. The role of problems to enhance pedagogical practices in the Singapore. The Mathematics Educator, 6(2): $15-31$.

Foong, P.Y. and P.L. Koay, 1997. School word problems and stereotyped thinking. Teaching and Learning, 18(1): 73-82.

Greer, B., L. Verschaffel and E. De Corte, 2002. The answer really is 4.5: Beliefs about word problems. In G. Leder, E. Pehkonen and G. Törner (Eds.), Beliefs: A Hidden Variable in Mathematics Education (Dordrecht, The Netherlands: Kluwer). pp: $271-292$.

Guven, B., F. Aydin-Guc and Z.M. Ozmen, 2016. Problem types used in math lessons: The relationship between student achievement and teacher preferences. International Journal of Mathematical Education in Science and Technology, 47(6): 863-876.Available at: https://doi.org/10.1080/0020739x.2015.1136438.

Hancock, C.L., 1995. Enhancing Mathematics learning with open-ended questions. The Mathematics Teacher, 88(6): 496-499.

Hembree, R., 1992. Experiments and relational studies in problem solving: A meta-analysis. Journal for Research in Mathematics Education, 23(3): 242-273.Available at: https://doi.org/10.2307/749120.

Hiebert, J., T.P. Carpenter, E. Fennema, K. Fuson, P. Human, H. Murray, A. Olivier and D. Wearne, 1996. Problem solving as a basis for reform in curriculum and instruction: The case of Mathematics. Educational Researcher, 25(4): 12-21.

Hitchcock, G. and D. Hughes, 1995. Research and the teacher: A qualitative introduction to school-based research. 2 nd Edn., London: Routledge.

Ho, K.F. and J.G. Hedberg, 2005. Teachers' pedagogies and their impact on students' mathematical problem solving. The Journal of Mathematical Behavior, 24(3-4): 238-252.Available at: https://doi.org/10.1016/j.jmathb.2005.09.006.

Ishida, J., 2002. Students' evaluation of their strategies when they find several solution methods. The Journal of Mathematical Behavior, 21(1): 49-56.Available at: https://doi.org/10.1016/s0732-3123(02)00102-5.

Kane, T.J. and D.O. Staiger, 2012. Gathering feedback for teaching: Combining high-quality observations with student surveys and achievement gains (Research Paper, MET Project). Seattle, WA: Bill and Melinda Gates Foundation.

Kılıç, S.D., 2011. Researching assessment and improvement approachment of students' performance level that exhibited in mathematics courses. Unpublished doctoral Thesis. Dokuz Eylül University, Institute of Educational Sciences, Izmir.

Kilpatrick, J., 1985. A retrospective account of the past 25 years of research on teaching mathematical problem solving. In E. A. Silver (Ed.), Teaching and learning mathematical problem solving: Multiple research perspectives. Hillsadle, N. J: Lawrence Erlbaum. Reporter: Lee Chun-Yi Advisor: Chen Ming-Puu. pp:1-15.

Krulik, S. and J.A. Rudnick, 1993. Reasoning and problem solving: A handbook for elementary school teachers. Boston: Allyn \& Bacon.

Lester, 1987. Available from http://ncm.gu.se/pdf/namnaren/3243_88_3.pdf [Accessed 23.10.2018].

Lianghuo, F., 2011. Performance assessment in Mathematics: Concepts, methods, and examples from research and practice in Singapore classrooms. Singapore: Pearson Education South Asia.

Lianghuo, F. and Z. Yan, 2000. Problem solving in Singaporean secondary Mathematics textbooks. The Mathematics Educator, 5(1/2): 117141.

Liljedahl, P.G., 2008. The AHA! experience: Mathematical contexts, pedagogical Implications. Theses (Faculty of Education)/Simon Fraser University.

Lofland, J., 1971. Analyzing social settings. Belmont, CA: Wadsworth.

London, R., 1993. A curriculum of non-routine problems. Paper Represented at the Annual Meeting of the American Educational Research Association, Atlanta, GA, April. (ERIC Document Reproduction Service No. ED359213).

Mahlios, J., 1988. Word problems do i add or subtract? The Arithmetic Teacher, 36(3): 48-52.

Marchis, I., 2013. Future primary and preschool pedagogy specialization students' mathematical problem solving competency. Acta Didactica Napocensia, 6(2): 33-38.

Neuendorf, K.A., 2002. The content analysis guidebook. Thousand Oaks, CA: Sage Publications Inc.

New Turkish Secondary Education Curriculum (M.E.B), 2018. (M.E.B, 2018). Available from http://mufredat.meb.gov.tr/Dosyalar/201813017165445-

MATEMAT\%C4\%BOK\%20\%C3\%96\%C4\%9ERET\%C4\%BOM\%20PROGRAMI\%202018v.pdf [Accessed 23.11.2018].

Niss, M., 2011. Competencies in mathematics education - potentials and challenges. What's the point? What's new? What do we gain? What are the pitfalls? XIII. Inter-American Conference on Mathematics Education, 26-30 June 2011, Recife (Brasil).

Özdogan, G. and F. Kula, 2007. Routine answers to non-routine problems. XVI. National Education Sciences Congress, Gaziosmanpasa University Education Faculty, 5-7 September, Tokat.

Özmen, Z.M., D. Taskin and B. Güven, 2012. Determining types of problem used for seventh grade by math teachers. Education and Science, 37(165): 1-16.

Pólya, G., 1945. How to solve it. Princeton, NJ: Princeton University Press.

Saravanan, V., 2005. Thinking schools, learning nations' implementation of curriculum review in Singapore. Educational Research for Policy and Practice, 4(2-3): 97-1 13.Available at: https://doi.org/10.1007/s 10671-005-1543-x.

Selden, A., J. Selden, S. Hauk and A. Mason, 1999. Do calculus students eventually learn to solve non-routine problems? (Report No. 19995). Cookeville, TN: Tennessee Technological University.

Selden, J., A. Mason and A. Selden, 1989. Can average calculus students solve non-routine problems? Journal of Mathematical Behavior, 8: $45-50$.

Swanson, H.L., M.J. Orosco and C.M. Lussier, 2014. The effects of mathematics strategy instruction for children with serious problemsolving difficulties. Exceptional Children, 80(2): 149-168.Available at: https://doi.org/10.1177/001440291408000202.

Turner, S.F., L.B. Cardinal and R.M. Burton, 2015. Research design for mixed methods: A triangulation-based framework and roadmap. Organizational Research Methods.

Van, D.H.-P.M., 1996. Assessment and realistic Mathematics education. Utrecht: CD-B Press/Freudenthal Institute, Utrecht University. 
Verschaffel, L., 2002. Taking the modeling perspective seriously at the elementary school level: Promises and pitfalls (Plenary lecture). In A. Cockburn \& E. Nardi (Eds.), Proceedings of the 26th Annual Conference of the International Group for the Psychology of Mathematics Education. School of Education and Professional Development, University of East Anglia, UK. 1. 64-82.

Verschaffel, L., E. De Corte and I. Borghart, 1997. Pre-service teachers' conceptions and beliefs about the role of real-world knowledge in mathematical modelling of school word problems. Learning and Instruction, 7(4): 339-359.Available at: https://doi.org/10.1016/s0959-4752(97)00008-x.

Ylldırım, A. and H. Şimşek, 2006. Qualitative research methods in social sciences. 5th Edn., Ankara: Distinguished Publishing.

Zhu, Y. and L. Fan, 2006. Focus on the representation of problem types in intended curriculum: A comparison of selected mathematics textbooks from Mainland China and the United States. International Journal of Science and Mathematics Education, 4(4): 609626.Available at: https://doi.org/10.1007/s 10763-006-9036-9. 